\title{
Evolution of Gender Role: Implications for Sustainable Development in Nigeria
}

\author{
Grace Funmilayo Olusegun Ph.D. Olusegun Edward Gbenga \\ Department of Guidance and Counselling,Ekiti State University, Ado- Ekiti, Nigeria \\ Music Department,College of Education, Ikere Ekiti
}

\begin{abstract}
From the time immemorial, culturally and socially there have been distinctive roles performed by different sexes in the society based on individual's gender identity. It is not farfetched that there have been disparity in the roles between male and female. This paper investigated gender roles as evolved in four periods namely, renaissance, baroque, classical and twentieth century. Renaissance period revealed that men and women have different roles in the society as masculine and feminine, appropriate for men and women. Females were expected to marry and be limited to domestic roles. Baroque period was highly spiritual devoted to different kinds of musical performance and men were actively involved but females were restricted. Classical period does not bring any conspicuous changes as women were still subjected to their husband and a symbol of domestic inferior without civic rights. Men were so powerful and given total freedom and rights. Twentieth century bring about equal opportunities in many areas like, education, marriage, society recognition and so on and appliances made domestic work easy. It is therefore recommended that both sexes should be allowed to perform their gender roles to enhance greater and sustainable development and that university students should desist from following the obsolete pattern of living.
\end{abstract}

Keywords: Gender, evolution, renaissance, baroque, classical, twentieth, roles.

DOI: $10.7176 / \mathrm{JEP} / 10-36-11$

Publication date: December $31^{\text {st }} 2019$

\section{Preamble}

Education is the basic human right and it has been recognized aright from the commencement of the universal declaration on human rights. Schools are formative on shaping how young people view themselves and others based on the roles performed by individuals in respect of their biological sex in accordance with their gender which is socially and culturally constructed. In the past, women are denied of good education, with the belief that they are meant for domestic activities and child bearing. Even in the areas of choice of career, science oriented courses are portrayed as a masculine pursuit in which women faces significant barriers to participate. Females were restricted to certain scientific fields like - home sciences, nursing, and child psychology to mention a few. In some cases, career goals are often based on predetermined ideas of gender roles, been justified by the stereotype that women are naturally more emitted to jobs that entails concentration, patience, dexterity and domestic experts rather than being creative. Whereas, all human, beings male and female should be free to develop his/her personal ability and make choices without prejudice. Culture and social values seems to have tremendously contributed to gender role disparity and if this trend continues, it could mar our economic development.

Influence of the antecedent of gender roles has become a fretful antisocial behavior in Nigeria tertiary institutions. The rate which university students engaged themselves in family way is alarming based on cultural believes asserted by Lonenz (2012) that females were only created for domestic and child bearing. As observed by the researcher, before the count of ten girls, four will be pregnant, inside the lecture room, cry of babies will be disturbing and distracting the attention of other students. Lots of unmarried students are already living with opposite sex as husband and wife. In actual fact, most of these relationships usually terminated at the campus gate in spite of the havoc it might have caused. Some were involving in multiple sexual relationships, different cases of sexual assaults on campuses mostly caused by male students. Studying in night class is already a problem, innocent students can no longer move freely on campus, they are highly apprehensive of what may befall them as found by Olusegun(2012). However, due to the problem constituted by this act, the unruly permissive behavior cannot continue to manifest, efforts to debase it must be intensified. The goal of this paper is to dig deep into the root of this problem and identified the etiological factors behind the occurrence and come out with probable strategies that can debase the act for sustainable development.

\section{Concept of Gender}

According to Handwerker,(1993) gender is defined as the socially imposed division of the sexes which was understood as one of the tools of patriarchy, a social system built on the biological foundation of human sexual dimorphism that allocated different roles, rights and responsibilities to male and females . Gender could also be described as a form of identity, located in and asserted by individuals rather than imposed from outside. It is a 
way of identifying humans as male and female or neither. Robert, (2014) asserted that gender is one of the organizing principles of the society. Gender refers to the set of expectations and norms linked to how women and men, girls and boys, should behave in a given society. It refers to as attitudes, feelings, and roles that is socially and culturally associated with a person's biological sex which are compatible with cultural expectations. It is our biological, social and legal status as men and women that influenced our operations in the society. According to World Health Organization (WHO) (2003), gender refers to the socially constructed roles, behaviours, activities, and attributes that a given society considered appropriate for men and women. Gender involves the physiological and biological attributes assigned by nature following by the imposition of the socially constructed roles, it exemplify the attributes that a society or culture constitute as masculine and feminine.

\section{Concept of Gender Identity}

Gender identity refers to personal identification with a particular gender role in the society. It is ones innermost concept of self and personal sense of being a man or woman. (a boy or girl). It is a person's sense of self as a member of a particular gender, because every individual's biological sex is directly tied to specific social roles and the expectations. It is how an individual perceive themselves and what they call themselves. One's gender identity can be the same or different from the sex assigned at birth, an individual may be identified with a role that corresponds to the sex assigned to them at birth. For example, somebody that was born with male sex characteristics and assigned as a boy and identify as a boy or man. Kemen, (2000) define gender identity as an internal characteristics of individuals, disclosed in their behaviour and what they say about themselves. It encompass all those things that a person says or does to disclose himself or herself as having the status of boy or girl, man or woman respectively. Individuals are conscious of this between the age 18 months and 3 years. Most people develop a gender identity the matches their biological sex. For some, however, their gender identity may be different from their biological or assigned sex. Some of these individuals choose to socially, hormonally and / or surgically change their sex to more fully match their gender.

\section{Concept of Gender Role}

The antecedent of gender role could be traced back to $14^{\text {th }}$ century till date as recorded by World Health Organization (2003) and this could be attributed to the fundamental facts about human existence which is peculiar to both sexes. Gender roles is the expression of one's identity, that is the way people acts, what they do and say, to express being a girl or a boy, a man or a woman, and the characteristics are shaped by the society and it varied greatly from one culture to the next, one ethnic group to the next, and from one social class to another. It is the peculiar roles, functions, norms, behavioural patterns and the expectations that are associated with male and females in the society. Culturally, masculine and feminine are socially constructed because Nigeria culture recognizes two basic gender roles: masculine (having the qualities attributed to males), and feminine (having the qualities attributed to females). Those who step out of their socially assigned gender roles are sometimes referred to as transgender. Historically and culturally, females are noted to be kept indoor performing domestic roles and care of the entire family particularly the husband and that of children are paramount. While men are to take up outside roles, particularly leadership roles

According to Kemen(2000), Gender roles are learned behaviours in a given community or society, or other special group which are affected by age, class, race, ethnicity, religion and by the geographical, economic and political environment. Change in gender roles often occurs in response to changing in economic, natural, or political circumstances, including development efforts. Children learn gender roles from an early age from their parents and immediate family members, their religion, culture, as well as the outside world, through television, magazines, and other means. Gender evolution simply means how gender evolve at the beginning of life on the planet.

Masculine is believed to be rational, autonomy, possessing power, active, aggressive, competitive and full of activities, thereby making them to be eligible to be outside and dominate everywhere, while masculine is to be emotionally tender, dependency, passive, nurturing, care giving which is the basis of oppression for women. Unfortunately, some of our university girls were now bending towards this unprogressive and oppressive believe. Nigeria has the highest population in Africa with almost 162.5 million people. The ratio of women is about $49 \%$. 80.2 million Adolescents and women as recorded by the National population census (2002). If this percentage of the Nigerian could be unproductive, it could hinder the global development in Nigeria. This paper examined gender roles from the renaissance period to twentieth century.

\section{The renaissance Period}

Renaissance is a french term meaning, rebirth, that is there was the awakening of ancient knowledge defined as an intellectual movement. The Renaissance is a period in history between the 14th and 17th centuries and bridging the Middle Ages to Modern history, a period of great cultural changes. This period witness the 
emergency of Italian masters. One of the great philosopher of this period is Protagoras who said that "Man is the measure of all things." This new thinking became manifest in art, architecture, politics, science and literature., The intellectual basis of the Renaissance was its own invented version of humanism, derived and rediscovered by this great classical philosopher. The changes of the Renaissance were not uniformly experienced. As a cultural movement, the major activities at this period encompassed development in the areas of education, economics, religion, marriage, legal, and societal value.

This period beginning with the 14th-Century educational reform. In politics, the Renaissance contributed to the development of the customs and conventions of diplomacy, and in science to an increased reliance on observation and inductive reasoning. Although the Renaissance saw revolutions in many intellectual pursuits, as well as social and political upheaval, it is perhaps best known for its artistic developments and the contributions of such polymaths. Various theories have been proposed to account for its origins and characteristics, focusing on a variety of factors including the social and civic peculiarities. It is perhaps no accident that the factuality of the Italian HYPERLINK "https://en.wikipedia.org/wiki/Italian Renaissance" HYPERLINK "https://en.wikipedia.org/wiki/Italian_Renaissance"Renaissance has been most vigorously questioned by those who are not obliged to take a professional interest in the aesthetic aspects of civilization-historians of economic and social developments, political and religious situations, and, most particularly, natural science-but only exceptionally by students of literature and hardly ever by historians of Art.

\section{Gender Roles in the Renaissance Period}

Throughout history, men and women have been assigned specific and different roles to which society prescribes standards and qualification according to Amber Zuber (2008). Renaissance is a period of emergence of creativity and new thinking but women were left out of this creativity. The value, social expectations, legal status, and rights of citizenship differed greatly between the sexes as well as among the classes. Men basically functioned as the ruling voice over all aspects of society, all forms of public and domestic authority were vested in men. Women had virtually no control over their role in the society. The most honorable life, was that which included not only scholarly activity, but also political and public service. Woman as a public reputation was dishonorable, a sure sign of immorality and scandal" (Pinker (2011). Women were excluded from any position of meaningful authority in any realm of society, only valued for their physical appearance because beauty was establish as a quality of life, it was placed at high esteem and only men had the capacity to assess which was beautiful and not beautiful. This is the only area where they are superior to men. --asserted that women are object to be viewed with pleasing affections, not with any sense of worth. Women were also valued for qualities that define them as submissive and passive. A woman's character should consist of specific attributions such as chastity, modesty, humility, constancy, temperance, piety, patience, and kindness Charles,(2000). Women was to tend to her household duties industriously, be silent most of the time and not speak out or argue and she must never be witty or clever" (Charlse, (2000). It becomes quite obvious that the value of women during the Renaissance was almost opposite that of men. Men had absolute authority while married women had virtually no rights as citizens. "Women differed from the men in their ability to be witnesses, make wills, act as guardians for their own children, make contracts, and own, buy , and sell property" (Mark,(1993). They were legally powerless in the society in which they lived. Only men had complete control over all constitutional matters. They also enjoy an educated capacity for reasoning, neither of which was possible for women". While married women had few rights within society, "single women, whether widowed or unmarried, could, if they were of full age, inherit and administer land, make a will, sign a contract, possess property, sue and be sued, without a male guardian or proxy. But married women had no such rights under the common law" (Murray, (1993).

Marriage is another important domain to examine in the study of Renaissance conceptions of gender roles. The duties of husband and wife were explicitly defined and expected to be followed by both men and women. The role of the husband is one of authority and dominance. Although, "the first duty which the husband has toward the wife is to love her, the next duty is to rule or govern his wife in all duties that properly belong to marriage, using his knowledge, wisdom, and judgement to maintain himself in the place that God intended him to have" (Camden 112). Women were seen as inferior in their abilities to run a household and make moral decisions. A woman's role as wife is also clearly defined. In the marriage contract must obey the husband. This obedience or submission extends not only to the performance of duties required by the husband, but also to the abstinence from those activities which are displeasing to him". Women who chose to become wives, which is the majority of the female population, agree to submit themselves to total control by their husbands. They move from living under the control of their fathers to living under the control of their husbands.

In education. "Intellectually, [women] were seen as limited. It was believed that a woman was by nature incapable of higher learning, being framed by God only for domestic duties Gary,(2008). Women were not only excluded from the educational opportunities offered to men, they were thought of as physically unable to learn the same materials men studied. Furthermore, "many men seem to have regarded the capacity for rational thought as exclusively male; women, they assumed, were led only by their passions" (Greenblatt 18). Women 
were unable to escape from their emotions long enough to learn something factual. This assumption is also related to but the coldness of woman makes her naturally fearful and timorous. And since women are weak physically, they must be weak morally and mentally" (James, Francis, Maurie \& Rosaline, (2018). This rudimentary conception of heat as a biological difference led people to believe that women were inferior to men in almost every capacity except those dealing with domestic duties is submissive, nurturing, emotional, and easily manipulated.

\section{Baroque Period}

The word baroque was derived from the Portuguese 'barocco' meaning irregular pearl or stone. The term was majorly used to describe music, first used to describe the period of art that followed renaissance in 1855 by the Swiss art historian Jacob, (2011) in an article in the journal Le Ciceone. He used the term to attack the movement for subverting the values of the renaissance period of art. This period was between $17^{\text {th }}$ to $18^{\text {th }}$ centuries, it followed the renaissance period. Art and music flourish this period, it acculturate drama presentation in music with characters singing instead of speaking. Baroque period focuses on a particular period of music, a convenient catch -all for of the richest and most diverse periods in music history. It also reflected the religious tension of the age mainly to reassert itself in the wake of the protestant reformation. This term has been widely used since nineteen century to describe the period in Western Europe art of music about 1600-1750. Some of the baroque composers are Monteverdi, Corelli and Vivaldi. Many of which originated in Italy. It was believed that music is a potent tool of communication and that it could arouse any emotion in its listener. With all the beauty attached to music and its forms, females are forbidden to perform as it was believed that their holiness especially during their menstrual period was not ascertained, hence, women roles was given to the castratos whose voices was scientifically tuned to meet the standard of the females which was fairly successful. Hence Geoffery Blainey, (2011) noted that women may also have been driven from Judaism to Christianity through the taboos and rituals related to the menstrual cycles, and a society preference for male over female children.

\section{Gender Role in the Baroque Period}

It is crystal clear that music phenomena are gendered because music are socially and culturally constructed. Muoz \& Palmaf,(2014), p, 989. He opine that, music is part of the construct of our sense of identity within the society. And that gender is repeatedly argued to be present at every stage of the communication triad. Women were still restricted as it was in the renaissance period, even this period that was music oriented, men still enjoy more freedom to perform. Gender role at this period seems controversial because all the music wrote for women is often performed by men as men sing women's parts even if the singer is a falsettist, is odd. Likewise there are female singers who are interested in exploring realism in portraying men on stage. But in opera, men only ever play women for comedy. There are some music that will be written for female that will be performed by men with a condition to be castrated. It was of recent that we found females having interest in exploring realism in portraying men on stage, women are only used for comedy in opera music. But there are certain roles that seems to be sung by certain voices. Mostly in Handel's composition some roles are gender blind, others are not.

\section{Classical Period (18 ${ }^{\mathrm{TH}}$ Century)}

Classical period could be traced to $1775-1885$. This period culminated in the master piece of G. F. Handel, new musical styles was developed and revealed in the event of keyboard and orchestral music, a transition from the baroque period to classical era. The name classical period was applied to the period because there is great interest in art and literature. The period marked the age of enlightment, philosophers like, philosophers like Rousseau, Voltaire, and Montesquieu wrote of the value of the human reasoning in overcoming the problem of the world. Musical scene at this period reflected the changes that took place in the society, reference to the public concerts which become an important part of the musical scene. The popular composers at this period according to Asmus,(2009) are, Franz Joseph Hayden 1732-1809, Wolfgang Amadeus Mozart 1756-1791, and Ludwig Van Beethoven 1770-1827.

\section{Gender role in the Classical Period}

Like in the past periods, classical period dies not bring any conspicuous changes as men were still regarded as the stronger sex, guided and trained to be intelligent, wise, courageous and determined. Also to be aggressive, while women were governed by their emotions, chastity, modesty, compassion, and piety and should be passive. It was revealed by Balk,(2014) that men were prone to violence, obstinacy, and selfishness, while women were perceived to be ruled by their bodies and their emotions, notably lusts, excessive passion, shrewishness and laziness. In marriage men were to rule over their wives and the total being of the woman belongs to the husband. Religious activities were performed by men, and women were restricted to few activities in the church. Political activities and positions of honour only meant for men. Education is not a must for women and little regard is 
given to women in the society. Legally, they were treated as weaker vessel.

\section{0th Century}

The 20th century was a century that began on January 1, 1901 and ended on December 31, 2000. It was the tenth and final century of the 2nd millennium. It is distinct from the century known as the 1900s which began on January 1, 1900 and ended on December 31, 1999. The 20th century was dominated by a chain of events that heralded significant changes in world history as to redefine the era: World War I and World War II, nuclear power and space exploration, nationalism and decolonization, the Cold War and post-Cold War conflicts; intergovernmental organizations and cultural homogenization through developments in emerging transportation and communications technology; poverty reduction and world population growth, awareness of environmental degradation, and the birth of the Digital Revolution. It saw great advances in communication and medical technology that by the late 1980s allowed for near-instantaneous worldwide computer communication and genetic modification of life.

The century had the first global-scale total wars between world powers across continents and oceans in World War I and World War II. Nationalism became a major political issue in the world in the 20th century. Mass media, telecommunications, and information technology (especially computers, paperback books, public education, and the Internet) made the world's knowledge more widely available. Technological advancements during World War I changed the way war was fought, as new inventions such as tanks, chemical weapons, and aircraft modified tactics and strategy. At the beginning of the period, Britain was the world's most powerful nation, having acted as the world's policeman for the past century. After World War II, most of the Europeancolonized world in Africa. During this period, Nigeria witness a great change.

\section{Gender role in the $20^{\text {th }}$ Century}

$20^{\text {th }}$ century was a significant time that and period in which gender played a significant amount of impact on today's society. Unlike in the past periods, society now recognize the importance of females as an entity of growth and development that should not be underrated. As opined by Hamiton, (1940), our society has placed more value on women, as women now have control over their roles in the society. Women now enjoy the same rights with men and have access public places. , although, men still have the ruling voice not at the detriment of women.

In marriage, husbands have the responsibility to fend for the family at all cost, and wives are to respect their husbands. Pressure on women to deliver male heirs has reduced according to Henry (2013). Household work no longer rest solely on women, husband usually assissssst in some areas and even technology has made household work easier unlike in the past periods. Men were to rule over their wives and the total being of the wife belongs to the husband. Husband should demonstrate the masculine traits of might in the areas of weakness of their wife, there is also sexual satisfaction and chivalrous concerns for females as a weaker vessel. Female's inferior social position was increasingly questioned campaign to eliminate by feminist writers in oppression. Although, male still expect to be violent and aggressive in some situations but male deviance has been regarded as crime and probably addressed as crime.

\section{Conclusion}

The antecedent of gender role as examined captured four periods, namely the Renaisance, Baroque, Classical and Twentieth century revealed men dominance over females exists. The first three periods as examined revealed that there is inequality in the roles performed by male and females in Nigeria context. Male dominance prevail over women in all ramification of life, they function as the ruling voice in education, politics, economy, likewise in public services. Even in domestic obligation, females were seen as inferior in their ability to run a household and make moral decision where they were noted for as experts. The only noticeable area in females' life is their bodily beauty which was regarded as a must to satisfy the interest of males. Female's paramount role is to take up domestic roles, satisfy their husbands sexually, caring pregnancy and nurturing their babies. In, the $20^{\text {th }}$ century, these roles changed drastically, women recognition is manifested in the society. There is free access to polities, education, legal rights and opportunity to function outside home and take up any job for financial gain. Husbands' shares home responsibility with their wives and technology made household work easier.

In an attempt to relate past role with the current roles, that is, $20^{\text {th }}$ century, when women were only regarded as being inferior to men with the role of housekeeping and child bearing. It could be noticed that this might be the possible reasons why female undergraduates have the mentality that their major role is childbearing, hence, they should hastily enter into family way to take up womanhood recognized role that was culturally and socially constructed.

\section{Implication for economic development}

Female's restriction to domestic and childrearing obligations could not aid economic development in this era of 
economic hardship with numerous demands. Therefore, Female's preference to take up womanhood role rather than to face their studies with all seriousness could have negative influence on their academic achievement. It will just be like a yoruba adage that goes thus; 'Eni baleeku meji leekan kan soso, yio padanu mejeeji. 'On this note, academic work with family responsibility may not yield to fruitful end result and actualization. Hence, hinders economic development.

There should be gender equality that will permit females to actively participated in all areas of life endeavors to change females mentality beyond domestic obligations. Females should be allowed to strife hard in their academics for a healthy competition with their male counterparts and put into action the popular saying that "whatever a man can do, a woman can do better" to enhance sustainable development in Nigeria.

\section{Based on the above, the following were recommended;}

- There is need for proper counselling, counsellor should organize individual and group counselling for the female students to let them know the effects of early exposure to womanhood obligations.

- University administrators should come out with a law that will forbid student pregnancy while still in the university.

- Women are hidden resources, we should invest in their lives by proving them with all their essential needs to avoid deceit from opposite sex.

- There must be award of excellence for responsible students.

- Immature marriage should be discouraged

- Encourage students towards self-actualization.

- Marital counsellors should educate female undergraduates that only females that has good certificate and job can only be recognized by men and enjoy their care.

- Girls and women have the potential to transform Nigeria, investing in them will improve productivity and growth.

- $\quad$ There must be Gender equality to enhance development in Nigeria,

\section{References}

- $\quad$ Asmus .E. P. (2009). The measurement of musical expression, in paper to Suncost C Tampa, PL).

- $\quad$ Balk W. L.L. (2014) Gender and the Performing Desmond e. sergent.

- Blainey, Geoffrey, (2011). A short History of Christianity. Mary lawal; Rowman and Littlefied. p43.ISBN 978- 1-4422-2589-3

- Charls Tilly (2003) "The politics of collective violence" Cambridge University Press p. 469. ISBNo-52153145-4. s

- Hamilton J.J. (1940). Greater Fredom for women following the civiwar. Old strict code is realized.

- Gary Rodger Weaver (1998). Culture, Communication .and Conflict. Simon 7 Schuster. P 474. ISBN O536-00373.4

- Handwerker, Penn. (1993). "Gender Power Differences between Parents and High-Risk Sexual Behaviour by their Children: AIDS/STD risk factors extend to a prior generation." Journal of Women's Health 2, (3):301.

- James Watson, Francis Crick, Maurice W ILKINS, and Rosalind Franklin'. Science History Institute,. Retrieved 20 March2018.

- Kemeh H. (2000).' Gender Roles'” In early modern European Society. 157-173 New York.

- Lorenz C. (2012) Income of Inqualities in Nigeria: Improving the lives of Girls and women executive summary.iii.

- Marek (1976). "'The Indochina Wars; Gret Power Involvement- Escalation and Disengagement "' Journal of Peace Resr=earch. Sage Pnblications. 13(2): 117. ISSN1460-3578 JSTOR 423343.

- Muoz Lina G. \& Palomaf. (2014) .Female enterpreneuraship in spain during the Nineteeth and Twentieth Centuries.

- Olusegun G.F. (2012). Sexual Coercion among University Females Students in South-West Nigeria. Unpublished Thesis submitted to the department of Guidance and Counselling, Faculty of Education, Ekiti - State University, Ado- Ekiti Pp83.

- $\quad$ Pinker, Stephen (2011). The Better Angel of Our Nature. Viking. ISBN 978-0-670-02295-3.

- Robert F. (2014) Gender Inequality still exist http:// www.stuf. Co-n2/world/Nig/60921207/Gender inequality- still -in -Nig-Polities.

- World Health Organization (.

- .WHO) (2003). Women's Health. The WHO Multi-Country Study on Women's Health and Domestic Violence against Women. Geneva, Switzerland. 